\title{
Announcements
}

Charles E. Culpeper Foundation Scholarships in Medical Science

The Charles E. Culpeper Foundation is currently accepting applications for its 1992 Scholarships in Medical Science Program designed to support the career development of academic physicians.

Up to three awards of \$100,000 per year for three years will be made to United States medical schools on behalf of candidates who are US citizens, who have received their MD degree from a US medical school in 1983 or later, and who

are judged worthy of support by virtue of the quality of their research proposals. All scientific research relevant to human health is eligible for consideration. No institution may nominate more than one candidate. In selecting awardees, emphasis will be on identifying young physicians with clear potential for making substantial contributions to science as academic physicians. Since January 1988, twelve physicians have been selected as Charles E.
Culpeper Foundation Medical Scholars, three each in the years 1988, 1989, 1990 and 1991.

Deadline for applications is August 15, 1991. Awards will be announced by January 15, 1992, for activation on or about July 1, 1992. Applications forms and instructions may be obtained by contacting the Charles E. Culpeper Foundation at Financial Center, 695 East Main Street, Suite 404, Stamford, CT 06901, USA.

Prize 'Biochemical Analysis 1992'

The German Society for Clinical Chemistry awards the prize ‘Biochemical Analysis’ every 2 years at the conference Biochemische Ana-lytik in Munch.

The prize of DM 50,000- is donated by Boehringer Mannheim GmbH for outstanding and novel work in the field of biochemical analysis or biochemical instrumentation or for significant contributions to the advancement in experimental biology especially relating to clinical biochemistry. Competitors for the prize 1992 (conference Biochemische Analytik, May 5-8, 1992) should submit papers concerning one theme, either published or accepted for publication between October 1, 1989, and September 30, 1991, before October 15, 1991, to:

\section{Prof. Dr. H. Feldmann}

Secretary of the prize Biochemical Analysis

Institut für Physiologische Chemie der Unịversität

Goethestrasse 33

D-8000 München 2 (FRG) 